\title{
AEROMAGNETIC MAP OF THE FRENCHTOWN AND PART OF THE RIEGELSVILLE QUADRANGLES NEW JERSEY AND PENNSYLVANIA \\ By
}

G. R. Boynton, D. R. Pittillo, and G. L. Zandle

\author{
GEOPHYSICAL INVESTIGATIONS \\ MAP GP-552
}

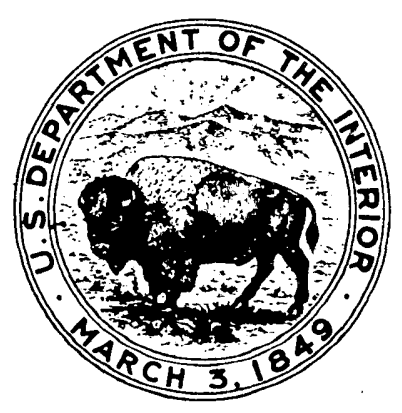

